\title{
On the Cost Structures of the End-of-life Product Logistics
}

\author{
Masashi Yamamoto*
}

\begin{abstract}
This paper analyzes the cost structure of the municipal waste collection in Japan. Since the municipality in Japan is responsible for dealing with the garbage generated by households, there is plenty of data regarding municipal waste in comparrison to private firms. Nevertheless, there is little research available which analyzes the end-of-life product logistics of municipal waste. This research aims to reveal some structural features of the end-of-life product logistics cycle. Based on more than 1,800 samples, this paper statistically shows that both waste collection and waste processing have a strong scale economy. In addition, this paper will also prove that the consignment to the private entity has made the cost of waste management cheaper in Japan.
\end{abstract}

keywords: Collection and Transport; Municipal Solid Wastes; Scale Economy; Waste Management

Submission Date: 6/22/2011 Revision Date: 10/25/2011 Acceptance Date: 10/25/2011

* Associate Professor, Center for Far Eastern Studies, University of Toyama, 3190 Gofuku, Toyama, Japan 930-8555, E-mail: myam@eco.u-toyama.ac.jp, Tel:+81-76-445-6455. 


\section{Introduction}

The year 2000 is referred to as "the first Year of the Resource Circulating Society". Various recycling laws have created the outline for the current Japanese recycling system, including the Basic Law for Establishing a Recycling-based Society and the Law for the Promotion of the Effective Utilization of Resources, which were both enacted in 2000. Because most of the transactions regarding end-of-life products (the economic system of products after disposal) are asymmetric information problems, it is difficult to prevent improper handling and illegal dumping without a robust legislative regime. Therefore, the establishment of a comprehensive legal system is especially important for the end-of-life products market.

Product distribution (how circulating resources are transported) tends to be overlooked when we examine the actual economy working with the regime. It is necessary to direct a mass-disposal society toward becoming a recycling-based society. To accomplish this goal, "Network Management", which manages the reverse logistics (the transportation network of used or disposed products), is necessary. It is as if the advanced modern society is made possible by managing forward logistics. In other words, to construct a superior recycling -based society, it is essential to have a smooth distribution system which can effectively transport used products.

To construct a smooth reverse logistics system, it is necessary to understand and analyze the cost structure, because the cost-efficiency of logistics is one of the most important indexes to reveal the smooth flow of transported items. For example, when considering the logistics of general waste in municipalities, the relationships between scale (the amount of waste collected) and cost need to be considered to create a smooth waste collection and transportation system. However, there are few analyses of the cost structures of waste collection and its transportation costs in Japan as far as the author knows.

This paper focuses on general waste collection and transportation, clarifies its characteristics, and derives policy implications from the perspective of cost structure.

\section{Review of Previous Research}

The quantitative analysis of general waste in Japan, as represented by Suwa and Usui (2007), has focused the waste production rate in the sense of the quantitative demand side of waste disposal services. The purpose of their research was to understand the impact of the "3R initiative", which is the basic principle for constructing a recycling-based society. 
Most importantly, their paper examined how the introduction of a recycling-related legislative system affected the amount of general waste production.

To analyze reduction in the amount of waste production, it is important to examine the reduction effect with relation to economic incentives such as fees. The increased introduction of economic incentive "unit-based pricing" policies by local governments which are responsible for managing general waste is particularly notable.1)

These unit-based pricing fees paid by citizens or service users do not cover all waste management costs. According to Yamaya(2007), for a municipality that charges comparatively high fees, the cost for a 40 little garbage bag is only 80 Yen. However, in 2005 , the total management fees for general waste management was 36.3 Yen per $\mathrm{kg}^{2}$ ). Converting 1 little as $0.25 \mathrm{~kg}^{3}$ ), 80 Yen for a 40 little garbage bag means 8 Yen per $\mathrm{kg}$. In the case of paying fees at the highest rate, this price is only a quarter of the actual cost.

The actual disposal costs are much higher than the imposed fees for a household. These fees are not intended to cover the whole waste disposal service but are meant to give citizens an incentive to become aware of waste reduction. Therefore, research on unit-based pricing often analyzes the demand-side behavior for waste management services. Sasao (2000) and Usui (2003) have also analyzed the waste management service needs in Japan.

Table 1.

Results of the Existing Research on Economies of Scale

\begin{tabular}{llll}
\hline & Cost Range & explained variables & Economies of Scale \\
\hline $\begin{array}{l}\text { Usui(2007) } \\
\text { All municipalities }\end{array}$ & All & Total Costs & Presence of Economies of Scale \\
\hline $\begin{array}{l}\text { Callan et al. (2001) } \\
110 \text { cities in Massachusetts State }\end{array}$ & All & Total Costs & $\begin{array}{c}\text { Absence of Economies of Scale } \\
\text { Presence of Density Economies }\end{array}$ \\
$\begin{array}{l}\text { Dubin and Navarro (1988) } \\
\text { 261 Cities in U.S.A. }\end{array}$ & Waste Collection & Average Cost & - \\
\hline $\begin{array}{l}\text { Stevens(1978) } \\
\text { 340 Cities in U.S.A. }\end{array}$ & Waste Collection & Total Costs & $\begin{array}{l}\text { Presence of Economies of Scale } \\
\text { Only cities with population below 50,000 }\end{array}$ \\
\hline $\begin{array}{l}\text { Hirsch(1965) } \\
\text { 25 Cities Around Saint Louis }\end{array}$ & Waste Collection & Average Costs & Absence of Economies of Scale \\
\hline
\end{tabular}

In contrast, research on the supply side of waste management services or municipal fees on general waste management are hardly ever performed. Only one known parametric analysis has been conducted by Usui (2007), who compared the models rigorously with panel data4). Usui (2007), for the first time, applied panel data analysis for a municipal cost

\footnotetext{
1) For more details on unit-based pricing policies, see Yamaya (2007)

2) This calculation is based on a press release by the Ministry of the Environment (2007)

3) Using the data from Yamaya's (2007, P61) actual value of a local government
} 
analysis of the Containers and Packaging Recycling Law in Japan. They found unique results, which showed that there were large differences in economies of scale depending on the population of the municipality.

Although the present research is closest to Yamamoto(2009) and Usui(2007) analysis on the use of data and model structures, my focus on general waste collection and transportation is significantly different from Usui (2007) because the entrustment contract which deals with general waste management, waste collection and waste disposal are treated differently in the contract process, and different companies often undertake different tasks. It differs from Yamamoto(2009) in that this paper utilizes a totally different econometric model and provides with rigorous the oretical background for the estimate.

Waste processing and final disposal in the equipment industry and reverse logistics (collection and transportation) in the network industry have different cost structures. Combining the two different industrial forms can cancel out each characteristic. Therefore, the strong point of this research in comparison with the existing research is that we can analyze and compare waste collection and transportation works and other waste management services separately. Although there is some past research which has partially examined waste collection and transportation in Japan, there is no research which has analyzed and compared both waste collection and transportation works and other waste management services for the entire country. This paper clarifies the differences in the cost structures by comparing the two.

\section{The Model}

\subsection{The Cost Minimizing Problem of Waste Management Services}

Let us assume that local governments intend to minimize the costs of waste management. The costs here are the expenses of waste collection, transportation and waste management. Construction and facility maintenance costs are not included. The model shown below makes the following specific assumptions ${ }^{5)}$.

4) There is an abundance of research on costs from the supply side outside Japane. The first researcher was Hirsch (1965). Dubin and Navarro (1988) and Callan and Thomas (2001) are representative of recent years.

5) As mentioned before, because fixed costs such as construction expenses are different from normal disposal expenses, they are excluded from this analysis. 


$$
\begin{gathered}
\min _{x, f, p} n \cdot\left[w_{x} x+w_{f} f\right]-p \cdot W(n, p, m) \\
\text { s.t. } \quad G(T, I, L, n x, n f, p)=0 \\
W(n, p, m)=I+L \\
T=\alpha W(n, p, m), \quad \alpha<1
\end{gathered}
$$

Here, $n$ indicates the frequency of waste collection and transportation. This chapter assumes that $n$ is determined exogenously for the municipality 6 ). $w_{x}$ is a wage rate, and $x$ indicates the labor time (per collection). $f$ is fuel (per collection), and $w_{f}$ indicates the fuel cost. $p$ represents unit-cost pricing for household waste. The amount of waste $(W)$ from each a household is dependent upon the number of collections $(n)$, the fees $(p)$, and the household income $(m)$.

Next, $G$ is a implicit production function of the waste management service. $T$ is the amount of waste collection and transportation, $I$ is the amount of waste processing (e.g., incineration), and $L$ is the amount of final disposal. Because local governments are responsible for general waste management, they need to manage all waste ( $W$ ) produced in their own area (shown in the constraints formula (3). Finally, the formula (4) shows that there is a case in which residents or a special company transport the wastes by themselves without using the local government's waste collection services.

The first order conditions for minimizing costs are the following:

$$
\begin{aligned}
& n \cdot w_{x}-\lambda \cdot \frac{\partial G(\cdot)}{\partial x}=0 \\
& n \cdot w_{f}-\lambda \cdot \frac{\partial G(\cdot)}{\partial f}=0 \\
& W(n, p)+p \frac{\partial W(\cdot)}{\partial p}-\lambda \frac{\partial G(\cdot)}{\partial p}=0 \\
& G(\alpha W, W-L, L, n x, n f, p)=0
\end{aligned}
$$

$\lambda$ is the Lagrange multiplier. The total costs $(C)$ are shown as follows:

6) Because general waste management is a local government affair, it is possible to change the frequency of collection and transportation legally. However, if the collection frequency changes often, there will be strong opposition from citizens. It is realistic to assume that the collection frequency is determined exogenously for the municipality in general waste management planning. 


$$
C=c\left(T, W\left(n, p^{*}, m\right), w_{x}, w_{f}, n\right)
$$

In the next section, an empirical analysis is conducted based on formula (9).

\subsection{Explanatory Variables and Expected Marginal Effects}

The independent variables are the amounts of waste collection and transportation (the output of waste management services) and waste disposal in waste processing and final disposal (hereafter referred to as the amount of waste discharged). The sources and definitions of these data will be explained in section 5 . The expected marginal effects for these variables are:

$$
\frac{\partial C(\cdot)}{\partial T}>0 \text { and } \frac{\partial C(\cdot)}{\partial W}>0
$$

Now, for the explanatory variables for fuel cost $\left(w_{f}\right)$, which is the main factor price in waste collection and transportation, we have chosen to use diesel fuel prices at each municipality. Because increases in the price of diesel increase total costs, we have assumed the following:

$$
\frac{\partial C(\cdot)}{\partial w_{f}}>0
$$

We presumed that the wage rate, which is the price of labor, is consistent throughout Japan. For a cross section analysis, we cannot calculate its effect, so the wage rate is not included in the estimate. Indeed, the wage rate in general might be different in each municipality. However, in the municipal solid waste business, because labor costs are uniformly determined by the "General Waste Disposal Accounting Standard", we assume that the wage rate is consistent throughout all municipalities.

Next, concerning the frequency of collecting household garbage, we assumed that the more the frequency increases, the higher the costs will become.

$$
\frac{\partial C(\cdot)}{\partial n}>0
$$


Collection frequency $(n)$ here means not only increases in the frequency of pick up at one place (station collection) but also increases in stop frequency for door-to-door collection. Therefore, we decided to use two explanatory variables for $n$ : "Frequency of monthly collection of flammable and non-flammable garbage" and "Door to door collection dummy". These details are given in the next section. This model assumes that the household wastes discharged from each household change depending on the presence or absence of a unit-based pricing policy.

$$
\frac{\partial W(n, p, m)}{\partial p}<0
$$

The equation above indicates that unit-cost pricing shift the demand curve to the left. Shifting the demand function when the average cost curve is downward, the effect of the total cost is not defined theoretically. The reason for this is that when the average cost curve is downward, the amount of waste discharged will be decreased and the average cost will increase. This relationship will be explained in more detail in section 3.3.

In order to find the impact on total cost of unit-based pricing when the economies of scale are confirmed, we set the dummy variable for a municipality that charges fees as 1 . The marginal effect is shown below.

$$
\begin{cases}\frac{\partial C(\cdot)}{\partial p}<0 & \text { if } \epsilon_{T C} \geq 1 \\ \frac{\partial C(\cdot)}{\partial p} \gtreqless 0 & \text { if } \epsilon_{T C}<1\end{cases}
$$

If there are economies of scale and the coefficient of the dummy variable for unit-based pricing is positive, the "hidden cost", which has not been discussed in previous charging policies for waste disposal, will be revealed.

Although (9) does not deal with it explicitly, a variable which represents the number of average household members in each municipality is included. We also add a dummy variable which indicates if a municipality is in the three metropolitan areas. The number of people in the average household has often been used in previous research. Increasing the number of household members tends to decrease the amount of waste discharged per person, and the marginal effect on the total cost will become negative. When the dummy variable for location in the three metropolitan areas is 1 , it is used to control congestion in waste collection and transportation, and the marginal effect is positive.

Furthermore, this paper analyzes management forms in waste management services as 
a policy variable. As mentioned previously, there is a wide field of options for each municipality to choose from in municipal solid waste management. We can divide the forms of management into four patterns ${ }^{7}$ ).

- Pattern 1: Only , municipal employees are involved in management.

- Pattern 2: Both the municipal employees and commissioned companies are involved.

- Pattern 3: Several commissioned companies are involved but no municipal employees.

- Pattern 4: Only one commissioned company is involved and no municipal employees.

With Pattern 1 as the standard, the empirical model includes three dummy variables, namely mixed for Pattern 2, privateonly for Pattern 3, and oneprivateonly for Pattern 4. It is usual that private consignment costs less. Moreover, when economies of scale are confirmed from the hypothesis that greater efficiency results when one private consigned company manages monopolistically, we presume a negative marginal effect from Patterns 3 and 4 .

\subsection{Economies of Scale and Economies of Scope}

"Economies of Scale" is one of the important considerations in analyzing the cost structure. Scale economies are often defined to be present when a $k$-fold proportionate increase in every input quantity yields a $k^{\prime}$-fold in output, where $k^{\prime}>k>1$ (Baumol et al. (1988)). In more general terms, there are economies of scale when the following holds true:

$$
\frac{\frac{d C(Q)}{C(Q)}}{\frac{d Q}{Q}}=\frac{d \ln C(Q)}{d \ln Q}<1
$$

Because (15) is simply a definition of elasticity, when the elasticity ( $\equiv \varepsilon_{T C}$ ) of the total cost of products is smaller than 1 , there are economies of scale. Moreover, using $M C$ for a marginal cost and $A C$ for an average cost results in the following:

7) Because of the condition of the data used, only the management forms of waste collection and transportation are analyzed. 


$$
\epsilon_{T C}=\frac{d C(Q)}{d Q} \frac{Q}{C(Q)}=\frac{M C}{A C}
$$

Therefore, it becomes $M C<A C$ when $\varepsilon_{T C<1}$. Now, we write the formula as follows:

$$
\frac{d A C}{d Q}=\frac{M C \cdot Q-C}{Q^{2}}=\frac{M C-A C}{Q}
$$

When there is economy of scale, the average cost decreases. Because this analysis uses log-log empirical models, it is possible to examine whether the economies of scale exist or not by using parameters after the estimated model is partially differentiated by $\ln Q$.

Let us define the economies of scope next. An economy of scope is the idea that one main constituent producing multiple products together costs much less than multiple main constituents producing multiple products. For example, when using two outputs, "the amount of waste collection and transportation" $(T)$ and "the waste processing and final disposal" $(I+L)$, we obtain the following:

$$
C\left(T^{*}, I^{*}+L^{*}\right)<C\left(T^{*}, 0\right)+C\left(0, I^{*}+L^{*}\right)
$$

The reason for finding economies of scope is normally the existence of physical (or intangible) inputs, which can be shared to produce each of the multiple productions. For example, waste collection and transportation services deliver waste to a designated transshipment space, and that space can be used again later for additional processes. For immaterial properties (i.e., know-how), waste sorting can be useful in both waste collection/transportation and waste processing.

Because we cannot observe (18) directly, the existence of the scope economy is replaced by the cost complementarities, which are defined as follows:

If the above equation is held, there are economies of scope ${ }^{8)}$. The economies of scope defined by cost complementarities can be examined from estimated parameters by using an estimated parameter after taking second derivatives of the estimated equation.

8) To be precise, because this is a sufficient condition, there is the possibility that economies of scope exist even when (18) is not satisfied. See Baumol et al. (1988, Chapter 4; p71-79) for the details. 


\section{Estimation Methods}

Our estimations use the OLS method. In order to examine the economies of scale with elasticity, we used a log-log model. To measure the economies of scope, the cross terms of output are included. The models used in the actual estimation are shown below:

$$
\begin{aligned}
\ln \text { TotalCost }= & \beta_{0}+\beta_{1}[\ln \text { twaste }]^{2}+\beta_{2} \ln \text { twaste }+\beta_{3}[\ln \text { cwaste }]^{2}+\beta_{4} \ln \text { cwaste } \\
& +\beta_{5}[\ln \text { twaste } \times \ln \text { cwaste }]+\beta_{6} \text { nhome }+\beta_{7} \ln n \text { colec }+\beta_{8} \ln n h h \\
& +\beta_{9} \text { unitprice }+\beta_{10} \ln \text { income }+\beta_{11} \text { largecity }+\beta_{12} \ln \text { fuelprice } \\
& +\beta_{13} \text { mixed }+\beta_{14} \text { privateonly }+\beta_{15} \text { oneprivateonly }+\epsilon
\end{aligned}
$$

The following is a brief explanation of (20) and a further explanation of the results with actual data will be explained in section 5. The left hand side (Total Cost) of (20) is either the total cost of collecting/transporting or processing in the municipality. twaste is the total amount of waste management and the equivalent of $W$ in (9). cwaste is $T$ and is the amount of waste collected and transported. nhome is a dummy variable that becomes 1 when the service is collecting waste at the front of each individual's house. ncolec is the number of collections in a fixed period. As mentioned in section 3.2, these variables are the equivalent of $n$ in (9).

unitprice is a dummy variable for when the municipality is charging for household waste collection, which means $P$ in (9). Additionally, income is $m$ in (9) and is the average taxable gain per person in each municipality. All $P, m$, and $n$ influence the size of $W$ (the amount of waste production). fuel price is $w_{f}$ in (9) and indicates the diesel fuel price. $n h h$ is the average number of household members, and largecity is a dummy variable that counts as 1 when the municipality is located in the three metropolitan areas (Tokyo, Aichi, or Osaka).

mixed, privateonly, and oneprivateonly in the bottom of (20) are all policy variables that are dummy variables showing how each municipality manages municipal solid waste services. mixed is the case when both municipal employees and commissioned companies are managing; privateonly is the case when several commissioned companies are managing; and oneprivateonly is the case when only one commissioned company is managing. There is also a case in which only municipalities are managing. All municipalities use one of these four patterns for municipal solid waste management services. 
The estimated parameter is $\beta_{i}$, and a cross sectional analysis is conducted in the next section using the data set from 2005.

\section{Data}

The data used in this research are all from the "waste disposal survey" from the Ministry of the Environment ${ }^{9}$ ). Additionally, the data of socio - economic activity aside from municipal solid waste are from the Ministry of Internal Affairs and Communications (2007).

\subsection{The Definition and Fundamental Statistics of the Data Used in This Research}

The Descriptive statistics of the data are shown in Table DFBasicStats.

\section{Table 2.}

Descriptive Statistics

\begin{tabular}{lrrrrr}
\hline \hline \multicolumn{1}{c}{ Variable } & Mean & (Std. Dev.) & Min. & Max. & $\mathbf{N}$ \\
\hline totalcost & 792158.9517 & $(2239681.8468)$ & 0 & 47370250 & 1844 \\
cwaste & 17637.2085 & $(44360.8808)$ & 0 & 819052 & 1844 \\
twaste & 28594.1752 & $(82067.6013)$ & 34 & 1640426 & 1844 \\
fuelprice & 104.2841 & $(2.3321)$ & 99.25 & 112.5833 & 1844 \\
nhome & 0.0765 & $(0.2658)$ & 0 & 1 & 1844 \\
ncolec & 10.4664 & $(3.1043)$ & 4 & 32 & 1844 \\
nhh & 2.8541 & $(0.3943)$ & 1.6336 & 4.4082 & 1844 \\
unitprice & 0.5277 & $(0.4994)$ & 0 & 1 & 1844 \\
income & 1.1318 & $(0.3383)$ & 0.4443 & 5.0977 & 1844 \\
largecity & 0.2196 & $(0.4141)$ & 0 & 1 & 1844 \\
mixed & 0.1139 & $(0.3178)$ & 0 & 1 & 1844 \\
oneprivateonly & 0.1703 & $(0.376)$ & 0 & 1 & 1844 \\
privateonly & 0.5266 & $(0.4994)$ & 0 & 1 & 1844 \\
\hline
\end{tabular}

9) However, a portion of data about the amount of waste collected in Tokyo's 23 wards are not included in the survey. Therefore, we downloaded and used information from the statistical information system of the borough government information and exchange center (http://www.research.tokyo-23city.or.jp/ accessed on August 31, 2007) 
The definition of each data is stated below. The total cost (total cost), a dependent variable, is the cost of municipal waste management (unit: thousand yen), which is a part of the waste management operating expenses shown in the waste disposal survey. Waste management operating expenses are defined as:

$$
\begin{aligned}
\text { Waste Operating Expenses } & =\text { Expenses for Construction and Improvement } \\
& + \text { Processing and Running Fees + Others }
\end{aligned}
$$

The total cost shown in this research is only the "processing and running fees" part of (21). For this variable, the data in the waste disposal survey is divided into each municipality's cost and the partial-affairs association's cost. A total of 1,844 municipalities which participate in the partial-affairs association ${ }^{10)}$ share all costs by adding the association's shared expenses to the municipality expenses.

Next, cwaste is the amount of municipality waste collection along with transportation and is defined as "direct and commissioned collecting volumes" (unit:ton). twaste is the total amount of the municipality's waste generation, which is defined as "planned collecting amount + direct transported amount + group collecting amount" (unit: ton). fuelprice indicates the diesel price, and the information is from the Oil Information Center of the Japan Energy Economics Research Institution 11); this variable represents the average value in 2005 (unit: yen/liter) ${ }^{12}$ ).

10) The total number of 598 associations in Japan in 2005.

11) http://oil-info.ieej.or.jp/price/price.html.

12) However, when there was no reliable data the municipality level, prefectural level data is used. 


\section{Estimated Results and Interpretation}

The estimated results of (21) are shown in Table 313 ).

Table 3.

Estimated Result

\begin{tabular}{|c|c|c|}
\hline Variable & Coefficient & (Std. Err.) \\
\hline $\ln$ twaste 2 & $0.1766^{* *}$ & $(0.0336)$ \\
\hline lntwaste & $0.4442^{\dagger}$ & $(0.2575)$ \\
\hline ln cwaste ${ }^{2}$ & $0.2090^{* *}$ & $(0.0280)$ \\
\hline ln cwaste & 0.1517 & $(0.2680)$ \\
\hline ln twaste $\times$ ln cwaste & $-0.3694^{* *}$ & $(0.0550)$ \\
\hline ln fuelprice & 0.4631 & $(0.4990)$ \\
\hline unitprice & $0.1187^{* *}$ & $(0.0199)$ \\
\hline nhome & $0.1153^{* *}$ & $(0.0311)$ \\
\hline $\ln$ ncolec & -0.0008 & $(0.0031)$ \\
\hline $\ln n h h$ & $-0.5214^{* *}$ & $(0.0877)$ \\
\hline ln income & $0.1690^{* *}$ & $(0.0461)$ \\
\hline largecity & $0.1686^{* *}$ & $(0.0250)$ \\
\hline mixed & -0.0038 & $(0.0308)$ \\
\hline oneprivateonly & $-0.1052^{* *}$ & $(0.0310)$ \\
\hline privateonly & $-0.1107^{* *}$ & $(0.0235)$ \\
\hline intercept & $4.2257^{\dagger}$ & $(2.3512)$ \\
\hline $\mathrm{N}$ & \multicolumn{2}{|c|}{1837} \\
\hline $\mathrm{R}^{2}$ & \multicolumn{2}{|c|}{0.9232} \\
\hline $\mathrm{F}_{(15,1821)}$ & \multicolumn{2}{|c|}{1837.8391} \\
\hline
\end{tabular}

Significance: $1 \%:^{* *}, 5 \%:^{*}, 10 \%:^{\dagger}$

To confirm whether the estimated cost function is consistent with the theory of cost functions, we need to check whether the increased production $(Q)$ increases the cost (i.e., whether the marginal cost is positive). Differentiating by $\ln Q$ :

$$
\frac{\partial \ln C(Q)}{\partial \ln Q}=\frac{\frac{d C(Q)}{C(Q)}}{\frac{d Q}{Q}}=\frac{d C(Q)}{d Q} \cdot \frac{Q}{C(Q)}
$$

Because the marginal cost $(\mathrm{MC})$ is $\frac{d C(Q)}{d Q}$, rearranging (22) for $\mathrm{MC}$ :

13) White's Robust Standard Errors are used. 


$$
M C=\frac{d C(Q)}{d Q}=\frac{\partial \ln C(Q)}{\partial \ln Q} \cdot \frac{C(Q)}{Q}
$$

To confirm the marginal cost, we can use two values which are differentiated in the estimated formula by $\ln Q$. Those two values are:

$$
\frac{\partial \ln \text { TotalCost }}{\partial \ln \text { twaste }}=2 \cdot \hat{\beta}_{1} \ln \text { twaste }+\hat{\beta}_{2}+\hat{\beta}_{5} \ln \text { cwaste }
$$

and

$$
\frac{\partial \ln \text { Totalcost }}{\partial \ln \text { cwaste }}=2 \cdot \hat{\beta}_{3} \ln \text { cwaste }+\hat{\beta}_{4}+\hat{\beta}_{5} \ln \text { twaste }
$$

\section{Table 4.}

Distribution of Marginal Cost

\begin{tabular}{crrrrr}
\hline \hline Variable & Mean & (Std. Dev.) & Min. & Max. & $\mathbf{N}$ \\
\hline MC for collection and transportation & 20.0276 & $(78.8598)$ & -1640.944 & 2756.6714 & 1837 \\
9 municipalities omitted & 21.7346 & $(64.5785)$ & 1.03 & 2756.6714 & 1828 \\
MC for waste management & 15.7015 & $(58.1938)$ & 1.1237 & 2485.5781 & 1837 \\
\hline
\end{tabular}

Table 4 summarizes the distribution of marginal costs calculated with (23). The sign of the average value is positive in both waste collection/transportation and waste processing, and it is consistent with the theory. For waste collection and transportation, the minimum value shows a large negative number because the amount of waste collection and transportation is comparatively smaller than the waste management amount in one part of the municipalities. The result of the calculation shows that only 9 out of 1,837 sample municipalities are negative, which is only $0.6 \%$ of the total ${ }^{14}$ ).

Let us now take a look at the economies of scale. Although the economies of scale are defined in (15), it is nothing other than (24) and (25). The results of the waste management $\ln ($ twaste $)$ and its square term $[\ln ($ twaste $)] 2$ are significant. However, for the results of waste collection and transportation, the square term $[\ln (\text { cwaste })]^{2}$ is significant, but $\ln ($ cwaste $)$ is not.

14) This result is also shown in Table MCdistribution, where the 9 municipalities which showed negative numbers have been excluded. 
Table 5 is the summary of the distribution of the elasticity based on (24) and (25).

\section{Table 5.}

The Estimated Results of Economies of Scale

\begin{tabular}{lccccc}
\hline \hline \multicolumn{1}{c}{ Variable } & Mean & (Std. Dev.) & Min. & Max. & N \\
\hline Waste Collection/Transportation & 0.4389 & $(0.0833)$ & 0.0419 & 0.673 & 1828 \\
Waste processing & 0.4356 & $(0.0815)$ & 0.2822 & 1.5809 & 1837 \\
\hline
\end{tabular}

According to this Table, both waste collection/transportation and waste management are largely below 1 on average, and this shows that there are economies of scale.

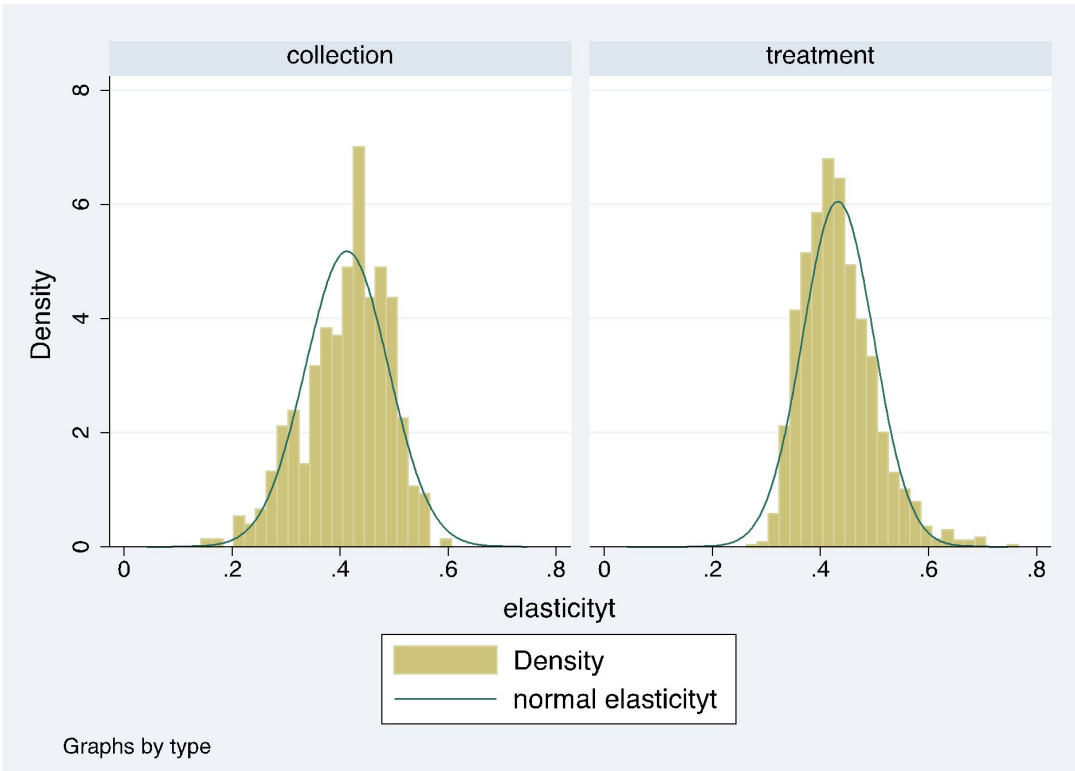

Figure 1.

Collection and transportation cost (left) and waste management cost (right)in production elasticity

Result 1. There are economies of scale for both waste collection/transportation and waste management as the average value of all municipalities. 
A sufficient condition for the economies of scope is when the product amount in the cross term parameter is negative, as shown in (20). This condition is given below:

$$
\beta_{5}<0
$$

Table 3 shows significantly negative results, which means that there are economies of scope in waste collection/transportation and waste management.

Result 2. There are economies of scope for both waste collection / transportation and waste management.

As can be seen in Table 2, the number of municipalities which charge fees for managing waste is about half of the total. Although it is confirmed that both waste collection/transportation and waste management have economies of scale (formula (14)), the effect of unit-based pricing for waste management services is still unpredictable from a theoretical standpoint. The result of Table 3 shows that unitprice is significantly positive. The demand function for waste management services is also not as sensitive to price. The increment of the average cost is greater than the reduction in the amount of waste production.

Result 3. Unit-based pricing for waste management increases the total cost of waste management services.

Next, we will take a look at household density as the average number of members in one household $(n h h)$. When household density is high, it is less work to collect per unit waste, and the cost to do so decreases. Aside from household density, the "density" in traffic congestion occurring from limited capacity for traffic can also influence the cost of waste collection and transportation. Garbage trucks cannot enter concentrated urban areas, so a garbage man must get off the truck, go to the main road, and collect the garbage. Because there was no suitable data to analyze such traffic density, we used a dummy variable, largecity. This dummy variable takes 1 when the municipality is located in the three metropolitan cities (Tokyo, Osaka, and Aichi) or other cities designated by ordinance. The results showed a positive coefficient with a significant level of 1\%. Traffic congestion may be one of the reasons for higher waste collection and transportation costs in urban cities.

The coefficient number of (flammable and recyclable garbage) collection frequency, which we presumed to be one of the factors in cost, was shown to be negative. In previous 
research, Porter (1998) reported that this cost is not sensitive to the collection frequency, so these results are consistent with the existing research. The implication is that it is still unclear how transportation frequency influences the cost.

Result 4. Increases in the stop frequency for collecting garbage at the front of each house show higher costs, whereas collecting garbage more frequently does not necessarily increase costs.

Next, we will consider how the form of management influences the cost. Although there is no previous research about the management form in waste management services in Japan, there are several studies from foreign countries. According to the existing research, using a private consignment minimizes the cost. Especially with private consignment, it is most effective when one company monopolizes management rather than multiple companies ${ }^{15)}$ because there are economies of scale.

Using the Ministry of the Environment (2007), four forms of management in waste collection and transportation are classified: "public management only"; "only (but several) private consignment (privateonly)"; "only one private consignment (oneprivateonly) ${ }^{16) " ;}$ and "a combination of direct and private management".

According to the estimated results of these dummy variables in Table 3, the privateonly and oneprivateonly coefficients are significantly negative. This proves that changing the management from direct to private can save costs. The results of the existing research show that the average cost is reduced with private monopolization. Our research also produced the same results.

Result 5. Private consignment for waste collection and transportation makes the total cost lower.

The local municipality's entrustment contract is provided in article 234 of the local government law. This contract requires the establishment of a general public bidding under the principle of competition. Occasionally, several municipalities conduct non-bid contracts (single tendering), and residents ask for legal proceedings, with the legal result of the non-bid contract for municipal solid waste management being approved ${ }^{17)}$. The Ministry of

15) For example, Dubin and Navarro (1988) reported that private monopolization is most effective. Additionally, Stevens (1978) showed that private monopolization is more effective than public monopolization.

16) Here, 'one company' means that they only consign with one company. This does NOT mean that they consigned with multiple companies and only one company operates. If the consignments are multiple, there is no practical benefit, such as economies of scale. 
the Environment's viewpoint is that the general public's bidding is unsuitable for the municipal solid waste management ${ }^{18)}$. It says that the most important consideration for the public regarding waste management is securing a discharge of the obligation rather than securing the most economical execution.

From the analysis above, we have proved that whether an entrustment contract is connected with a non-bid contract is not the primary issue from an economic efficiency point of view. The more important issue is to stop the direct management of waste services and to further privatized consignment.

\section{Conclusion}

The analysis in this research concentrated on the costs of municipal solid waste, especially waste collection and transportation costs. The results of this research show that the production elasticity of both waste management and waste collection, as well as transportation are smaller than 1. Therefore, we empirically showed that they both have economies of scale. Although the previous research conducted on economies of scale is vague, this research made it clear by analyzing waste management services as multiple output industries. We also analyzed the management form of waste collection and transportation in waste management services. The results show that private consignment minimizes the cost given the premise of natural monopoly in waste collection and transportation. Recently, there has been some criticism of private consignment by municipalities through non-bid contracts. However, it is important to concentrate on reducing direct management by municipalities and promoting private consignment in odrer for cities and customers to benefot from cost efficiencies.

\section{Acknowledgement}

The author is grateful for the comments by Collin Mckenzie (Keio University), Eiji Hosoda (Keio University) and Jung Ung Min (Inha University).

17) Akinori Kimura (2009) "Introducing the Competition Principle in Municipal Solid Waste Collection and Transportation Work: Maintenance and Commercialization of Environmental Hygiene Strategic Research in Management", vol. 3, pp. 239-250.

18) Mr. Akihiro Kasuya, the director of the Waste Management Countermeasure Department in the Ministry of the Environment, gave a lecture called "There is No Illegality in Non-bid Contracts for Waste Management" at the National Cleaning Federation (March 2006) 


\section{REFERENCES}

Baumol, William J., Panzer, John C. and Robert D. Willig (1988) Contestable Markets and the Theory of Industry Structure, revised edition, Academic Press.

Callan, Scott J. and Janet M. Thomas (2001) "Economies of Scale and Scope: A Cost Analysis of Municipal Solid Waste Services", Land Economics, Vol. 77 (4), pp548-560.

Dubin, Jeffrey A. and Peter Navarro (1988) "How Markets for Impure Public Goods Organize: The Case of Household Refuse Collection," Journal of Law, Economics, and Organization, Vol. 4, no. 2, pp. 217-241.

Hirsch, Wrner Z. (1965) "Cost Functions of an Urban Government Service: Refuse Collection," Review of Economics and Statistics, Vol. 47, pp. 87-92.

Ichinose, Daisuke and Masashi Yamamoto (2011) "On the Relationship Between Provision of Waste Management Service and Illegal Dumping", Resource and Energy Economics, vol. 33(1), pp. 79-93.

Japanese Ministry of Environment (2009) State of Discharge and Treatment of Municipal Solid Waste (each year).

Kinnaman, Thomas C. and Don Fullerton (2000) "Garbage and Recycling with Endogenous Local Policy," Journal of Urban Economics, Vol. 48,pp. 419-442.

Ministry of Environment (2008) State of Discharge and Treatment of Municipal Solid Waste. (each year, in Japanese).

Porter, Richard (1998) Economics of Waste, Resources for the Future.

Sasao, Toshiaki (2000) "An Analysis Considering the Regional Factors of Effects of User Fees and Sorted Collection for Solid Waste Serveice on the Reduction of Waste, " Journal of the Japan Society of Waste Management Experts, 11(1), 1-10. (In Japanese)

Stevens, Barbara J. (1978) "Scale, Market Structure, and the Cost of Refuse Collection," Review of Economics and Statistics, Vol. 60, pp 438-448.

Suwa, Tatsuo and Takehiro Usui(2007) "Estimation of Garbage Reduction and Recycling Promotion Under the Containers and Packaging Recycling Law and Garbage Pricing," Environmental Economics and Policy Studies, Vol. 8, no. 3, pp239-254. 
Usui, Takehiro (2007) "A Cost Structure Analysis of Municipal Solid Waste Management Using Panel Data," Journal of the Japan Society of Waste Management Experts, 18(6), 417-425.(In Japanese)

Yamaya, Shusaku (2007) Pricing Garbage, Maruzen Publishing (In Japanese)

Yamamoto, Masashi (2009) "An Economic Analysis of Collection and Transport of Municipal Wastes in Japan", Review of Environmental Economics and Policy Studies, Vol. 2, no. 1, pp. 39-50. (In Japanese) 